\title{
BMJ Open Ectopic pregnancy: exploration of its global research architecture using density-equalising mapping and socioeconomic benchmarks
}

\author{
Dörthe Brüggmann,, ${ }^{1,3}$ Jana Kollascheck, ${ }^{2}$ David Quarcoo, ${ }^{2}$ Michael H Bendels, ${ }^{2}$ \\ Doris Klingelhöfer, ${ }^{2}$ Frank Louwen, ${ }^{3}$ Jenny M Jaque, ${ }^{1}$ David A Groneberg ${ }^{2}$
}

To cite: Brüggmann $D$, Kollascheck J, Quarcoo D, et al. Ectopic pregnancy: exploration of its global research architecture using density-equalising mapping and socioeconomic benchmarks. BMJ Open 2017;7:e018394. doi:10.1136/ bmjopen-2017-018394

- Prepublication history for this paper is available online. To view these files please visit the journal online (http://dx.doi org/10.1136/bmjopen-2017018394).

Received 26 June 2017 Accepted 15 August 2017

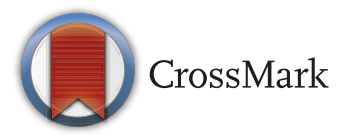

${ }^{1}$ Department of Obstetrics and Gynecology, Keck School of Medicine of USC, Los Angeles, California, USA

${ }^{2}$ Division of Female Health and Preventive Medicine, Institute of Occupational Medicine, Social Medicine and Environmental Medicine, Goethe-University, Frankfurt

${ }^{3}$ Department of Gynecology and Obstetrics, Goethe-University, Frankfurt, Germany

Correspondence to Dr Dörthe Brüggmann; prevention@uni-frankfurt.de

\section{ABSTRACT}

Objective About $2 \%$ of all pregnancies are complicated by the implantation of the zygote outside the uterine cavity and termed ectopic pregnancy. Whereas a multitude of guidelines exists and related research is constantly growing, no thorough assessment of the global research architecture has been performed yet. Hence, we aim to assess the associated scientific activities in relation to geographical and chronological developments, existing research networks and socioeconomic parameters.

Design Retrospective, descriptive study.

Setting On the basis of the NewQIS platform, scientometric methods were combined with novel visualising techniques such as density-equalising mapping to assess the scientific output on ectopic pregnancy. Using the Web of Science, we identified all related entries from 1900 to 2012.

Results 8040 publications were analysed. The USA and the UK were dominating the field in regard to overall research activity (2612 and 723 publications), overall citation numbers and country-specific H-Indices (US: 80, UK: 42). Comparison to economic power of the most productive countries demonstrated that Israel invested more resources in ectopic pregnancy-related research than other nations (853.41 ectopic pregnancy-specific publications per 1000 billlion US\$ gross domestic product (GDP)), followed by the UK (269.97). Relation to the GDP per capita index revealed 49.3 ectopic pregnancy-specific publications per US\$1000 GDP per capita for the USA in contrast to 17.31 for the UK. Semiqualitative indices such as country-specific citation rates ranked Switzerland first (24.7 citations per ectopic pregnancy-specific publication), followed by the Scandinavian countries Finland and Sweden. Low-income countries did not exhibit significant research activities.

Conclusions This is the first in-depth analysis of global ectopic pregnancy research since 1900. It offers unique insights into the global scientific landscape. Besides the USA and the UK, Scandinavian countries and Switzerland can also be regarded as leading nations with regard to their relative socioeconomic input.

\section{INTRODUCTION}

Around $2 \%$ of zygotes implant outside the uterine lining and form an ectopic gestation. ${ }^{1}$
Strengths and limitations of this study

- We compiled the first concise depiction of the worldwide scientific productivity related to ectopic pregnancies.

- The New Quality and Quantity Indices in Science platform was used to evaluate the scientific output regarding quantitative and qualitative aspects, geographical and chronological developments, existing research networks and socioeconomic benchmarks. The method combines scientometric methods and density-equalising mapping projections in a reliable and standardised way.

- The Web of Science focuses on English journals. It is a weakness that non-English articles are underrepresented in our analysis.

- We analysed citation-based parameters, which rather reflect the recognition of the research in the scientific community than truly measure quality.

Frequently, the products of conception grow in the fallopian tube. Other implantation sites are the ovaries or the cervix. Affected patients may face significant morbidity or even mortality. ${ }^{1}$ During the last decades, transvaginal ultrasound and beta-human chorionic gonadotropin (beta-HCG) levels became part of the clinical routine ${ }^{2-6}$ leading to the timely detection of ectopic pregnancies and better patient outcomes. ${ }^{7-9}$ First scientific publications describing therapeutic measures for ectopic pregnancies date back to the 16th century. Since then, thousands of studies tackled the most pressing questions in the field. ${ }^{10-12}$ Numerous discoveries improved diagnosis and management and shaped the clinical guidelines we are using today. ${ }^{13}$ Despite these hallmark advances in clinical care, ectopic pregnancies pose a significant burden on million women around the globe: In the USA alone, costs related to the condition were estimated at around US $\$ 1$ billion in $1990 .{ }^{14}$ Although the mortality associated 
with ectopic gestations was halved in industrialised countries since the $1980 \mathrm{~s},{ }^{15}$ the condition constitutes a major cause of death continents like Asia and Africa. ${ }^{16}$

A multitude of disciplines such as OB/GYN, Family Medicine, Internal Medicine and Surgery are involved in the management of ectopic pregnancies. Also, related research attracts the interest of scientists worldwide addressing the issue from a clinical, basic science and public health perspective. To carry out research according to identified shortcomings, establish global networks and allocate funds, scientists and funding institutions have to be aware of the global scientific landscape related to ectopic pregnancy research. Thus, this study provides a first comprehensive assessment of the research performance in the field and identifies trends in the related literature by a scientometric approach. ${ }^{1718}$ Therefore, we identified all ectopic pregnancy-related publications indexed in the Web of Science until 2012. These items were (1) analysed in reference to their content and citations describing geographical and historical developments, (2) research networks were identified and (3) the country-specific productivity was related to socioeconomic variables. Furthermore, we present the most cited publications related to ectopic pregnancies. These studies cover key discoveries in the field and provide the scientific fundament for many clinical decisions made daily around the globe.

\section{MATERIALS AND METHODS \\ NewQIS study protocol}

We employed the 'New Quality and Quantity Indices in Science' (NewQIS) platform to assess global ectopic pregnancy research in a standardised, reliable and objective way. ${ }^{17} 18$ This tool combines scientometric techniques to evaluate scientific productivity and density-equalising mapping (DEMP) ${ }^{19}$ to generate global maps according to analysed parameters. ${ }^{20-23}$

\section{Data source}

The database Web of Science (WoS, Thomson Scientific) was used to conduct this study. We selected this data source because it allows the assessment of publication activity similar to the PubMed database, but facilitates a thorough citation analysis for the research in focus. ${ }^{24} 25$

\section{Search strategy}

The following search term was used: 'ectopic pregnanc*' OR 'ovarian pregnanc*' OR 'cervical pregnanc*' OR 'tubal pregnanc*' OR 'abdominal pregnanc*' OR 'extrauterine pregnanc *' OR 'ectopic gestation*' OR 'ovarian gestation*' OR 'cervical gestation*' OR 'tubal gestation*' OR 'abdominal gestation*' OR 'extrauterine gestation*'. We performed a 'Topic' search, and the term was inserted into the WoS search fields 'title', 'abstract' and 'key words' to identify the total number of published items related to ectopic pregnancies.

\section{Timeframe}

The analysed timeframe for research on ectopic pregnancy encompassed the years between 1900 (01-01) and 2012 (31-12). Results from 2013 onwards were not considered due to incomplete data acquisition (ie, citation rate $(\mathrm{CR}))$ at the time the study was performed.

\section{Data analysis and categorisation}

Metadata were retrieved in Plain Text Format as described in previously published NewQIS studies. ${ }^{26}{ }^{27}$ Bibliometric details were analysed with respect to quantitative and semiqualitative aspects such as originating countries, languages, journals, citations, cited references, year published and subject areas. Subject area categories are assigned to every journal and its publications by the Journal Citation Reports (provided by the Institute of Scientific Information) during the publication process. These standard categories can be retrieved via WoS. For our analyses, these original WoS categories have been used.

As semiqualitative items describing the recognition of publications by the scientific community, the number of citations, CRs and the modified H-Indices (HI) were investigated, as previously described. ${ }^{28}$ Therefore, the citation numbers were retrieved for each publication and the average citations per item (CR) were calculated. Regression analysis was used to investigate the timely evolution of ectopic pregnancy research.

After the transformation of the raw data to excel programme charts and analysis, the findings were illustrated in numerous diagrams and visualised by the use of DEMP. The algorithm for this procedure was published by Gastner and Newman. ${ }^{19}$ In DEMPs, the territories of the different countries were resized in proportion to our selected variables such as the distribution of country-specific numbers of published items, average CRs and H-Indices.

\section{Socioeconomic analysis}

In order to assess research output with regard to the economic power of the most active countries, the publication activity was related to the Gross Domestic Product (GDP) and the GDP per capita in current US\$, as described earlier. ${ }^{29}$ As defined by the World Bank, the 'GDP at purchaser's prices is the sum of gross value added by all resident producers in the economy plus any product taxes and minus any subsidies not included in the value of the products. It is calculated without making deductions for depreciation of fabricated assets or for depletion and degradation of natural resources. Data are in current US\$. Dollar figures for GDP are converted from domestic currencies using single year official exchange rates. For a few countries where the official exchange rate does not reflect the rate effectively applied to actual foreign exchange transactions, an alternative conversion factor is used' (Source: http:// databank.worldbank. org/data/Views/Metadata/ MetadataWidget. aspx? Name $=$ GDP $\% 20($ current $\% 20$ 
US \$) \&Code=NY.GDP.MKTP.CD\&Type=S\&ReqType $=$ Metadata $\&$ ddlSelectedValue $=\&$ ReportID $=43 \% 20$ $570 \&$ ReportType $=$ Table) .

The World Bank also provides the following definition for the indicator 'GDP per capita': The 'GDP per capita is defined as gross domestic product divided by midyear population. GDP is the sum of gross value added by all resident producers in the economy plus any product taxes and minus any subsidies not included in the value of the products. It is calculated without making deductions for depreciation of fabricated assets or for depletion and degradation of natural resources. Data are in current U.S. dollars' (Source: http:// databank.worldbank.org/data/Views/Metadata/ MetadataWidget aspx? Name $=$ GDP $\% 20($ current $\% 20$ US \$) \& Gode=NY.GDP.MKTP.CD\& Type $=S \&$ Re qType $=$ Metadata $\& d d l$ SelectedValue $=\&$ ReportID $=43 \% 20$ $570 \&$ ReportType $=$ Table $)$.
Analysis of international ectopic pregnancy research collaborations

To investigate international research collaborations, the affiliations of all identified ectopic pregnancy-related publications were screened as described earlier. ${ }^{30} 31 \mathrm{In}$ brief, if at least two authors, who were working in different countries, contributed to one ectopic pregnancy-related publication, this relationship was defined as a collaborative publication. To visualise the productivity of collaborations for each pair of countries, a vector was calculated. Its line width and shade of grey is proportional to the number of depicted collaborations. ${ }^{2432}$

\section{RESULTS}

\section{Global ectopic pregnancy research activity}

We identified 8040 ectopic pregnancy-related publications issued from 1900 to 2012; these were cited 86680
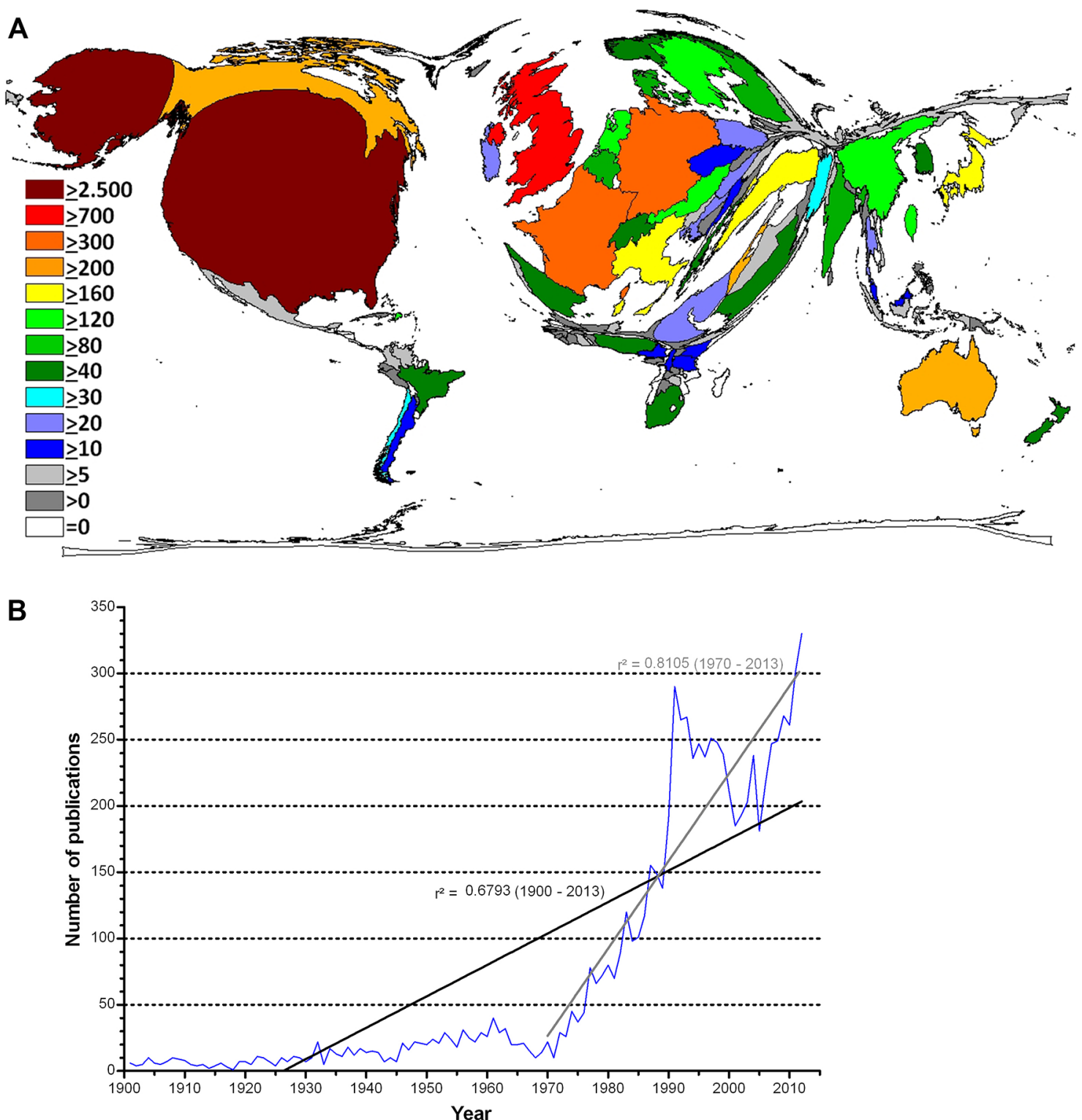

Figure 1 Publication output. (A) Global density-equalising mapping of ectopic pregnancy publications. The area of each country is scaled in proportion to its total number of ectopic pregnancy-related publications. Colours encode numbers of ectopic pregnancy publications. (B) Timely evolution of ectopic pregnancy-related publications. 
times. These items (92.4\%) were written in English and published by researchers from 76 different countries. US-American researchers authored 2612 publications accounting for $32 \%$ of all ectopic pregnancy-related publications. The USA was identified as the country with the highest number of publications worldwide (figure 1A). The UK was positioned second with 723 ectopic pregnancy publications, followed by Germany (370 publications), France (366 publications), Israel (248 publications), Canada (215 publications), Australia (203 publications), Italy (179 publications), Japan (169 publications), Turkey (162 publications), China (159 publications), Sweden (151 publications), the Netherlands (134 publications), Austria (124 publications) and Taiwan (122 publications). Since North America, Western Europe and Australia were responsible for the majority of research output associated with 'ectopic pregnancy', their country sizes appear inflated in the DEMP analysis (figure 1A). Major parts of Asia (except China and Taiwan), Russia, Africa and South America occupied only small areas on the cartogram. The analysis of the timely evolution led to a regression coefficient of 0.6793 for the period from 1900 until 2012 and of 0.8105 for the period from 1970 until 2012 (figure 1B). This indicated a strong increase of global research activity in the past 40 years.

\section{Socioeconomic analysis of ectopic pregnancy research}

In order to assess the relative magnitude of the countries research activities in relation to their economic wealth, the two indicators GDP and GDP per capita were used for our evaluation. The analysis of publication activity in relation to the most productive countries' GDP demonstrated that Israel published the highest amount of ectopic pregnancy-specific research relative to its GDP: 853.41 publications per US $\$ 1000$ billion GDP. It was followed by the UK with 269.97 ectopic pregnancy-specific publications per US\$ 1000 billion GDP, Turkey (196.79 publications per US $\$ 1000$ billion GDP) and the USA (155.77 publications per US\$ 1000 billion GDP) (table 1).
When the ectopic pregnancy publication activity was related to the GDP per capita, the USA again gained the leading position with a level of 49.3 ectopic pregnancy specific publications per US $\$ 1000$ GDP per capita. This benchmarking largely resembled the total publication activity analysis with the exception of Turkey, which climbed from tenth to third position due to its extremely low GDP per capita (table 1).

\section{Global citation analysis}

Citation analysis of all country-specific publications demonstrated a leading position of the USA. US-American publications dedicated to ectopic pregnancy research received a total of 39404 citations (figure 2A). It was followed by the UK with over 8000 citations, France (4423 citations), Canada (3578 citations), Israel (3057 citations) and Sweden (3349 citations). DEMP analysis regarding the citation activity was similar to the cartogram reflecting absolute publication numbers: the map represents nearly no citations for African, South American or Asian countries leading to a minimised appearance of these areas whereas North America and Europe are depicted increased in size (figure 2A).

The calculation of the country-specific H-Index (figure 2B) showed a leading position of the USA with 80 ectopic pregnancy-related publications being cited at least 80 times. The USA was followed by the UK with a country-specific H-Index of 42, Canada (H-Index: 36), France (H-Index: 35), Israel (H-Index: 31), Sweden (H-Index: 30), Finland (H-Index: 29), the Netherlands (H-Index: 29), Belgium (H-Index: 25) and Germany (H-Index: 25). Again, countries from Africa, Eastern Europe, Latin America or Russia exhibited very low rates.

The results of the country-specific CR (figure 2C) contrasted all other benchmarks since Switzerland ranked first with a CR of 24.7 , followed by the Scandinavian countries Finland and Sweden with CR of 20.9 and 20.2 , respectively.

Table 1 Socioeconomic analysis of ectopic pregnancy research of the 10 most active countries. Sources for GDP and GDP per capita in 2013: http://data.worldbank.org/indicator/NY.GDP.PCAP.CD

\begin{tabular}{lcclll}
\hline Country & $\begin{array}{l}\text { Number of } \\
\text { publications }\end{array}$ & $\begin{array}{l}\text { GDP in US\$1000 } \\
\text { billion }\end{array}$ & $\begin{array}{l}\text { Publications/GDP } \\
\text { in US\$ 1000 billion }\end{array}$ & $\begin{array}{l}\text { GDP per capita } \\
\text { in US\$ 1000 }\end{array}$ & $\begin{array}{l}\text { Publications /GDP per } \\
\text { capita in US\$ 1000 }\end{array}$ \\
\hline Israel & $248(5)$ & $0.2906(10)$ & $853.41(1)$ & $36.05(8)$ & $6.88(6)$ \\
UK & $723(2)$ & $2.6781(5)$ & $269.97(2)$ & $41.78(6)$ & $17.31(2)$ \\
Turkey & $162(10)$ & $0.8232(9)$ & $196.79(3)$ & $10.99(10)$ & $14.75(3)$ \\
USA & $2612(1)$ & $16.7681(1)$ & $155.77(4)$ & $52.98(2)$ & $49.30(1)$ \\
\hline France & $366(4)$ & $2.8102(4)$ & $130.24(5)$ & $42.63(5)$ & $8.59(4)$ \\
\hline Australia & $203(7)$ & $1.5604(8)$ & $130.09(6)$ & $67.47(1)$ & $3.01(10)$ \\
Canada & $215(6)$ & $1.8389(7)$ & $116.92(7)$ & $52.31(3)$ & $4.11(9)$ \\
Germany & $370(3)$ & $3.7303(3)$ & $99.19(8)$ & $46.26(4)$ & $8.00(5)$ \\
Italy & $179(8)$ & $2.1369(6)$ & $83.77(9)$ & $35.48(9)$ & $5.05(7)$ \\
Japan & $169(9)$ & $4.9195(2)$ & $34.35(10)$ & $38.63(7)$ & $4.37(8)$ \\
\hline
\end{tabular}

GDP, gross domestic product. 


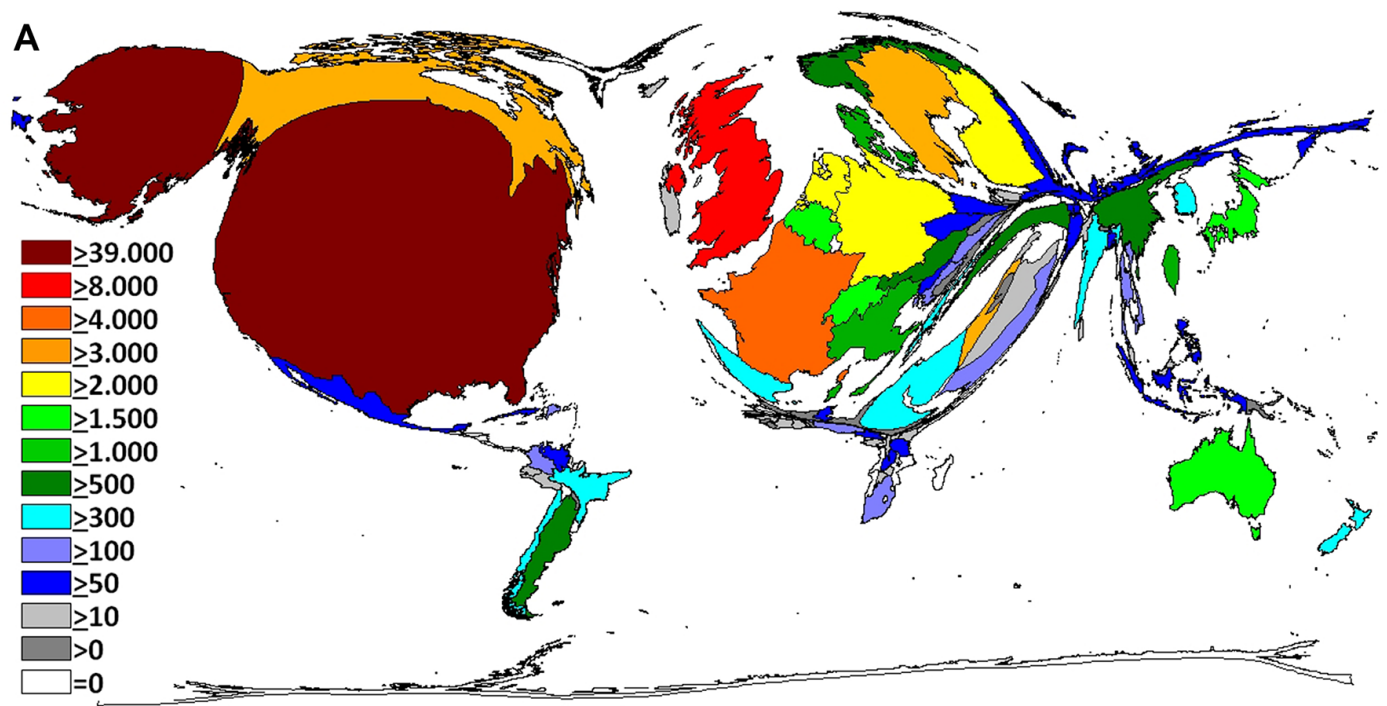




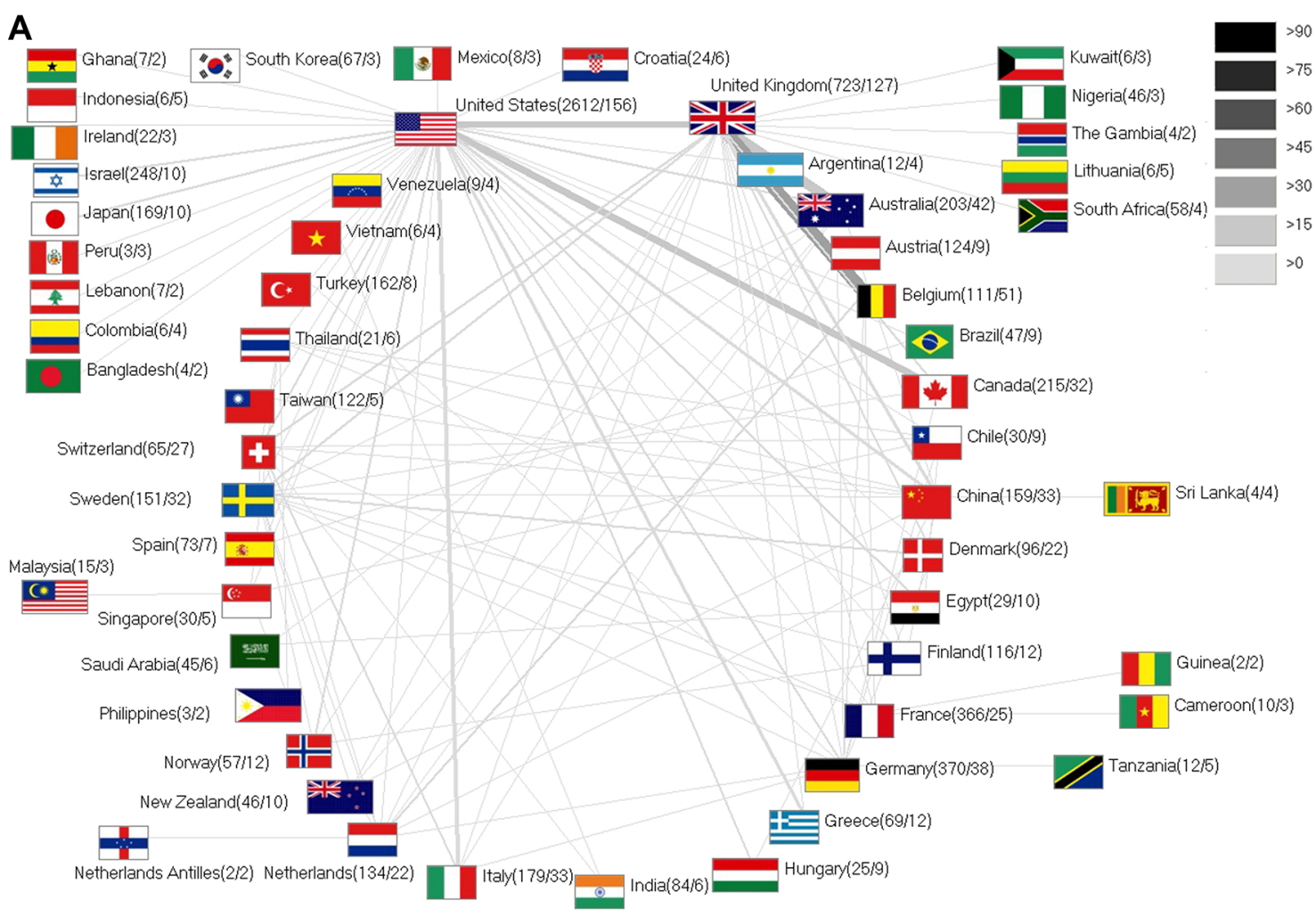

B

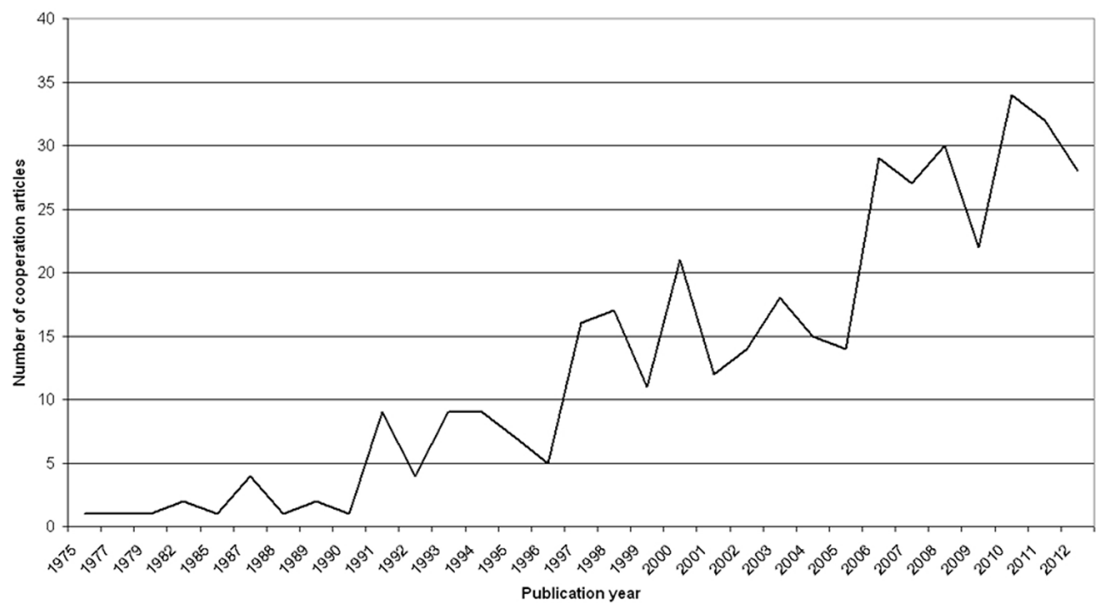

Figure 3 International collaboration. (A) Net diagram of international ectopic pregnancy-related collaborations. Line width and grey scale encode numbers of ectopic pregnancy-related collaborations. Numbers in brackets indicate number of ectopic pregnancy-related publications of a specific country/number of ectopic pregnancy-related collaboration articles of a specific country. (B) Timely evolution of number of ectopic pregnancy-related international collaborations per year.

\section{Cooperation articles}

Out of the 8040 ectopic pregnancy-related publications, only 397 were published within international collaborations. This equates a relatively small percentage of $4.9 \%$. With $82.1 \%$ (326 publications), bilateral collaborations were the most common type of established collaborative efforts, followed by trilateral (51) cooperations. The USA was the leading country with 156 collaborations followed by the UK with 127 international relationships. The most frequent bilateral collaboration was set up between the UK and Belgium with 37 joint studies. Interestingly, 51 out of the 111 total studies from Belgium arose from international collaborations, which equals a percentage of $45.9 \%$ (figure 3A). In comparison, the USA was characterised by a ratio of 156 collaborative publications out of $2612(6 \%)$, the UK by $17.6 \%$ and Germany by $10.3 \%$. A continuous increase in the numbers of collaborations was present until 2010 with 34 collaborative publications in this year (figure 3B).

\section{Subject area analysis}

The timely evolution in subject categories of ectopic pregnancy-related publications was analysed since 1973 and the proportion of the different subject areas was investigated (figure 4A). Articles can be assigned to more than one category, hence percentages of more than 100 were possible. From the beginning until 2012, 'Obstetrics and Gynaecology' remained the most prominent category. 

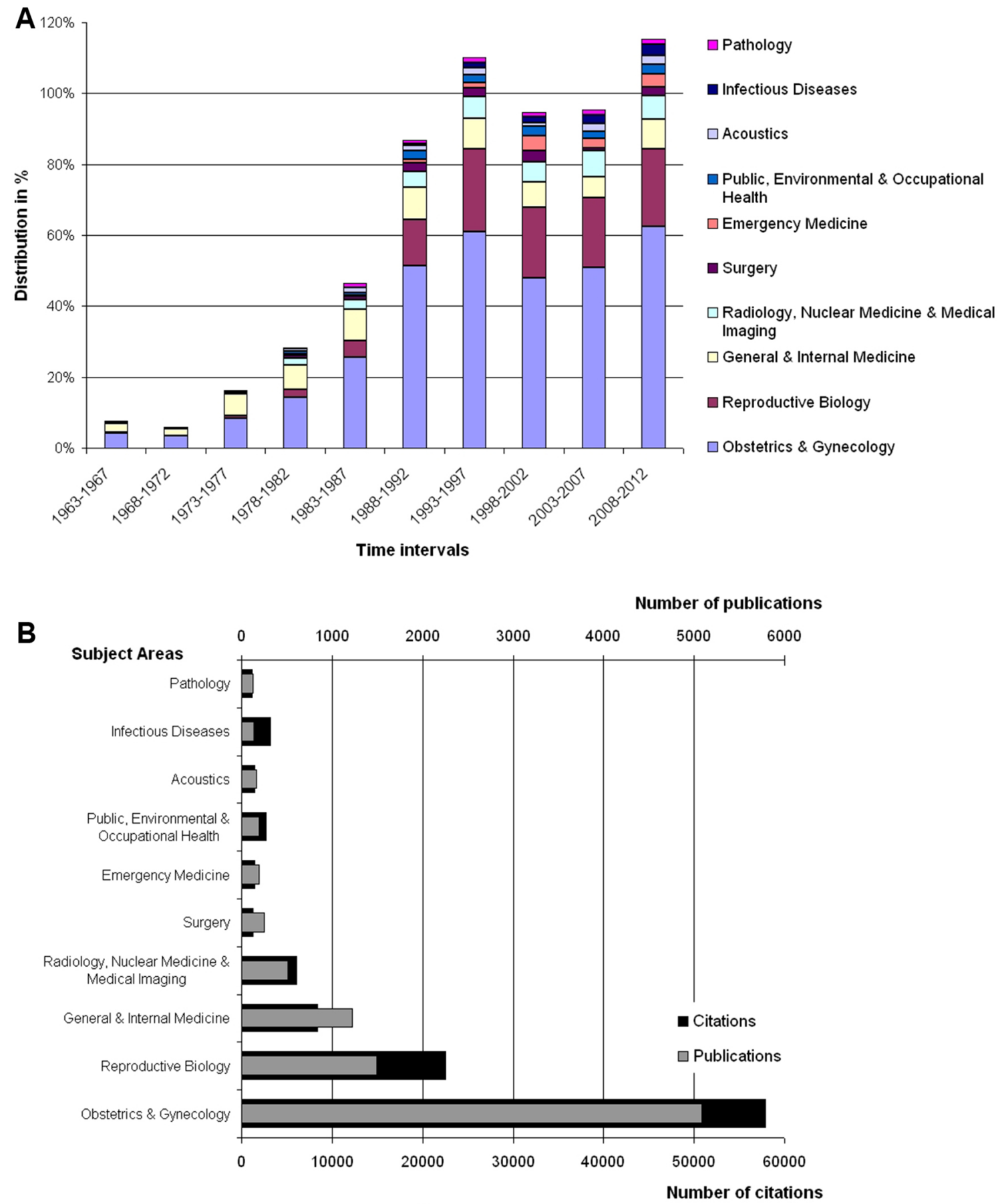

Figure 4 Subject area analysis. (A) Timely evolution of subject areas assigned to the ectopic pregnancy-related publications in 5-year periods. Proportion of the 10 most assigned subject areas in 5-year intervals in order to gain insights into the field activity. (B) Citation analysis of the 10 most assigned subject areas of all ectopic pregnancy-related publications.

'Reproductive Biology' gained importance after 1988. The field diversified in 1978 when research was also published in the categories of 'Emergency Medicine' (since 1978) and 'Pathology' (since 1983). Overall, the percentages of all assigned subject categories remained relatively constant with no rapid increase of one particular area within the past 20 years. A small but constant proportion of publications was attributed to the area of 'Public, Environmental and Occupational Health', which indicates that scientists also focused on public health issues related to ectopic pregnancy.
We identified the leading, most impactful publication categories based on item and citation count (figure 4B). The primary areas of ectopic pregnancy-research were 'Obstetrics and Gynaecology' and 'Reproductive Biology'. The 5100 publications assigned to 'Obstetrics and Gynecology' were cited 57879 times. 'Reproductive Biology' with 1496 publications was cited 22545 times. When CRs were analysed, the highest rate was present for the subject area 'Infectious Diseases' with 24.02 citations per ectopic pregnancy-related publication. The frequently assigned subject areas 'Reproductive Biology' and 'Obstetrics and 


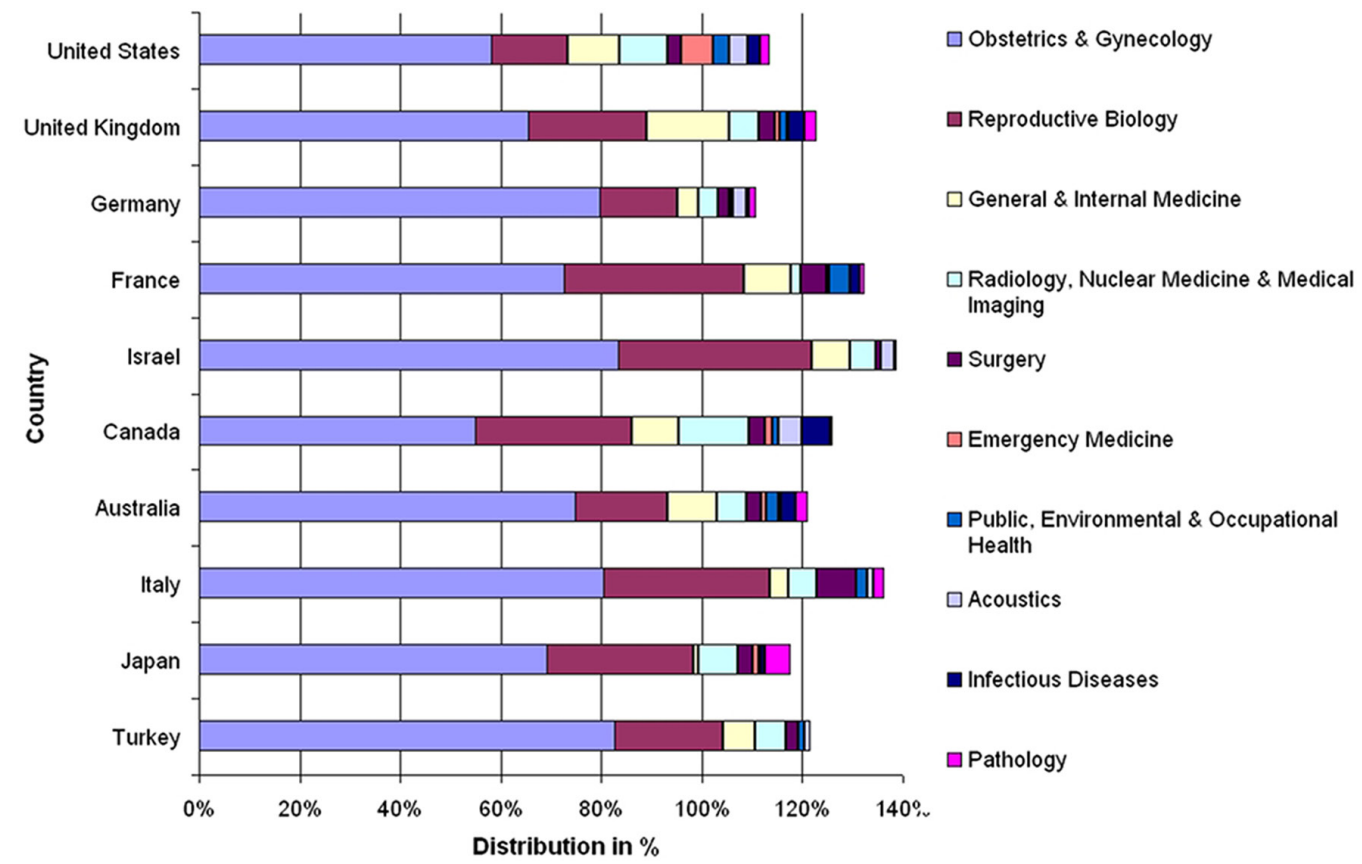

Figure 5 Country-specific analysis of assigned subject categories. Analysis was performed of the 10 most active countries in ectopic pregnancy research in order to identify regional differences in ectopic pregnancy research.

Gynaecology' were characterised by CRs of 15.07 and 11.37 respectively.

We performed a subject area analysis for the most productive countries aiming to pinpoint the particular focus of publications issued by researchers in these nations: in France, a high volume of 'Public Health'-related work was published. This finding underlines the nation's interest to allocate considerable resources to public health issues in context with ectopic pregnancies. A relatively high percentage of public health-related ectopic pregnancy research originated from the USA when compared with other countries, for example, Japan. Also, a high percentage of publications originating from the USA were allocated to the category of emergency medicine (figure 5). We identified the key publications in the field of ectopic pregnancy research, which were cited 200 times or more (table 2).

\section{Journal analysis}

We carried out an analysis of the most publishing journals in the field of ectopic pregnancy research (figure 6). Here, 'Fertility and Sterility' published the most articles on ectopic pregnancy (689 publications), followed by the 'American Journal of Obstetrics and Gynecology' (653 publications), 'Obstetrics and Gynecology' (466 publications), and 'Human Reproduction' (396 publications). These four journals belong to the top ranked journals in gynecology and obstetrics with impact factors more than 4.5. Regarding the average CR among the 15 most publishing journals, 'Obstetrics and Gynecology' received the highest rate with 20.5 citations per article $(\mathrm{CR}=20.5)$. We found the 'British Journal of Obstetrics and Gynecology' $(\mathrm{CR}=17.3)$ in second position. It was ranked 14th regarding the total number of publications (95 publications). It existed until 2012 and was continued as 'International Journal of Gynecology and Obstetrics' that ranked eighth regarding total publication numbers (166 publications) and reached an average CR of 5.93. Actually, the publication performance of both journals should be summed up, resulting in 261 publications and a $\mathrm{CR}=10.05$.

Regarding the CR, 'Human Reproduction' was positioned third $(\mathrm{CR}=16.9)$ and was ranked before the 'Lancet' (CR=14.4 and 129 publications). Among the 15 most publishing was only one non-English journal-the German journal 'Geburtshilfe und Frauenheilkunde' (ranked ninth with 156 publications on ectopic pregnancy and a $\mathrm{CR}=3.1$ ). It is the official publication platform of the German Society of Gynaecology and Obstetrics. Among the 15 most publishing journals, seven are published in the UK, four in the USA, two in Germany and one in Australia and Scandinavia, respectively.

\section{DISCUSSION}

Accounting for a percentage of $2 \%$ of all first-trimester pregnancies in the USA, ectopic gestation is a very common complication of pregnancy. It should therefore merit a high degree of interest within the scientific community. Hence, this NewQIS study ${ }^{17} 18$ is focused on this condition and presents the first multifaceted analysis of the related global research architecture using DEMP analysis tools. ${ }^{19}$ Additionally, we selected 15 'publication classics' that were defined as key articles in the field based on 200 and more citations. These key publications provide relevant background information for individual scholarship, practice and research endeavours. 


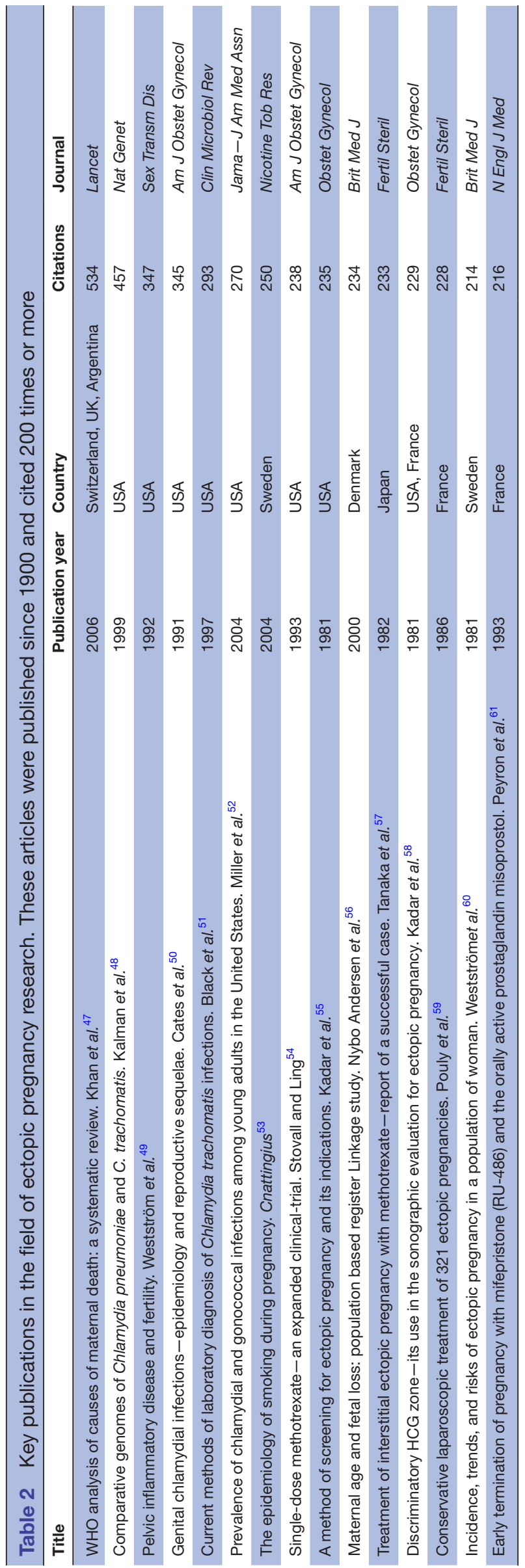

In total, we analysed 8040 publications related to ectopic pregnancies. The USA was identified as the country dominating the field. With regard to total publishing activities, it is important to compare ectopic pregnancy research to other disease entities or to the field of $\mathrm{OB} / \mathrm{GYN}$ in general: a recent study by Aleixandre-Benavent $e t$ al focused on trends in reproductive medicine research over a period of 10 years. ${ }^{33}$ It was the authors' objective to study the publication activity metrics from 2003 to 2012 and to shed a light on the clinical, social and epidemiological implications of this relatively new but rapidly emerging field. As outcome measures, they analysed most productive and frequently cited investigators, institutions and countries as well as specific areas of research and scientific collaborations. The authors found that 90 investigators with more than 1000 citations had jointly published 4010 articles. The most-cited study groups were located in the Netherlands, Belgium, Spain, the USA and the UK, and collaborative studies have been increasing. It was concluded that reproductive medicine research has attained scientific interest and importance. Also, the increase in (inter) national collaborations seems to be the key to the field's success. In contrast to Aleixandre-Benavent $e t a l$, we focused on a single disease entity and encompassed more than 100 years of research. Besides monitoring the scientific output, we also related the numbers to the economic power of investigated countries in order to dissect the real interest of single nations in research related to a particular condition. Therefore, we related the ectopic pregnancy-related research activities to the total GDP and the GDP per capita. We found that the USA still dominated when GDP per capita index was used. However, when related to the total GDP index, Israel exhibited the highest contribution of ectopic pregnancy research in relation to its overall economic power.

We compared the present data to other OBGYN entities such as polycystic ovary syndrome (PCOS) or ovarian cancer $^{34}{ }^{35}$ : A published study on PCOS that covered the years between 1900 and 2014 reported a total of 6261 PCOS-specific publications and 703 international research collaborations in the Web of Science. As in the present study, the USA was identified as the most active country in total and collaborative research activity. ${ }^{34}$ In the socioeconomic analysis, the USA was also ranked first concerning PCOS-related publications per GDP, followed by the UK, Italy and Greece. ${ }^{34}$ For ovarian cancer research, 23378 reports were identified for the period 1900-2014. Denmark was positioned at the first place with a total of 1293.2 calculated ovarian cancer-specific articles per US $\$ 1000$ billion GDP. ${ }^{35}$ Other gynaecological topics, which have been screened for scientific productivity, were predominantly related to breast cancer ${ }^{36-39}$ : Glynn et al presented an in-depth evaluation of breast cancer research. The authors screened publications from 1945 to 2008 also using the NewQIS platform. ${ }^{39}$ They identified 180126 breast cancer-associated items; these had been cited 4136224 times. In comparison to our data on ectopic pregnancies encompassing a time span 


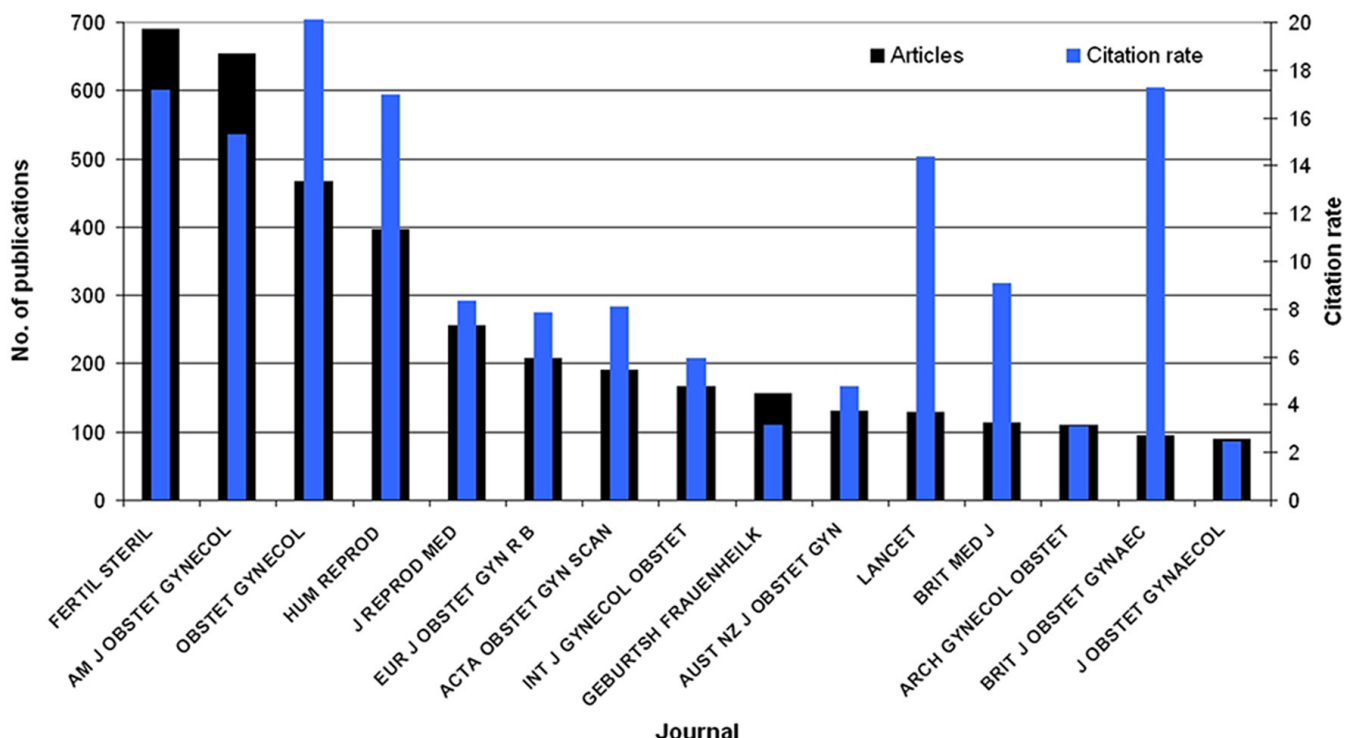

Journal

Figure 6 Number of articles and average citation rate of the most publishing journals on ectopic pregnancy.

of 112years, breast cancer research has produced a more than 20 times greater scientific output in a period of slightly over 60 years. One reason for this discrepancy is that breast cancer accounts for the most common malignancy among women, with an estimated 231840 new cases diagnosed in the USA in 2015 alone.$^{40}$ Hence, this disease receives large amounts of public awareness. Also, significant volumes of scientific resources are allocated to support research in this area. In breast cancer, the USA produced the greatest publication output $(\mathrm{n}=77101$; $42.8 \%)$, followed by the UK $(n=18357 ; 10.2 \%)$ and Germany $(n=12529,7 \%) .{ }^{39}$ This ranking of the most productive nations was similar to ectopic pregnancy research with $32.5 \%$ ectopic pregnancy-related publications originating from the USA, around $9 \%$ from the UK and $4.6 \%$ from Germany. The percentage of total global research activity exhibited by US-American institutions is higher in breast cancer research than in ectopic pregnancy research.

'Smoking in pregnancy' is another area of OB/GYN research that was studied. ${ }^{41}$ Here, 10043 related publications were identified in a period from 1900 to 2012. As in our investigation and the presented breast cancer study, the highest number of scientific works was published by the USA $(35.5 \%)$, followed by the UK $(9.9 \%)$. For both countries, we documented similar percentage values and the highest modified H-Indices of 128 (USA) and 42 (UK) for ectopic pregnancy research activities. When citation performance is compared, it is evident that research in 'smoking and pregnancy' receives a higher attention in the scientific community than scientific endeavours related to 'ectopic pregnancy' since the 10043 publications in the field of 'smoking and pregnancy' were cited 112136 times (11.2 citations per publication) versus 8040 ectopic pregnancy-related publications that received 86680 citations (10.8 citations per publication).
In our study, the USA occupied the top position among all countries in regard to overall publication and citation numbers as well as the H-index. We explain this finding with the outstanding research environment and funding provided for scientists in the USA. Further, we hypothesise that the prominent position of the USA might also be linked to a possible bias: four of the most prolific journals in the field are based in the USA; they provide an impactful publishing platform for ectopic pregnancy research (as shown in our journal analysis). US-American reviewers are known for their favourable evaluation of publications submitted by local researchers leading to a predominance of US-American works among the accepted manuscripts. ${ }^{42}{ }^{43}$ But we regard this 'reviewer bias' overall as limited, and it can be stated that the observed dominance of the USA is also common in other, non-OB/GYN medical specialties. In a study that analysed 5527558 published items authored in all areas of medicine over the last 50 years, the following ranking of total research activity was found ${ }^{44}$ : the USA was the leading nation, followed by Japan, Germany, the UK, France and Italy. ${ }^{44}$ Furthermore, it can be clearly stated that Japan does not exhibit comparable activities in the field of ectopic pregnancy research with only 169 publications in the present set of data. This finding could be linked to a lower prevalence of ectopic pregnancies in Japan compared with other nations translating into disregard of the topic among local scientists and funding institutions. However, epidemiological data on the exact rates of ectopic pregnancies or pelvic inflammatory disease in Japan are lacking. Also, data on maternal mortality attributed to ectopic pregnancies are sparse. For the early nineties, ectopic pregnancy-related maternal mortality was reported at $4 \%$ in Japan compared with $13 \%$ in the USA (data collected until 1989). ${ }^{45}{ }^{46}$ Since this difference could indeed reflect a lower impact of ectopic pregnancies on the public health of Japanese women, this fact 
may explain a lacking interest of Japanese institutions to foster research on this topic.

We identified a small number of international collaborations in the field of ectopic pregnancy research. The rate of $4.9 \%$ is substantially lower than in other fields. Additionally, we documented a very small number of ectopic pregnancy-related publications investigating public health aspects. These findings indicate a low awareness of this subject matter in terms of ectopic pregnancy research, which is contrasting the major disease burden this condition poses on women-especially in low-income countries with high rates of pelvic inflammatory diseases and only limited access to diagnostic and treatment procedures. Therefore, future research should pay attention to these problematic issues and focus on fostering collaborative efforts, involving developing countries in research networks and conducting projects in the field of public health.

\section{CONCLUSIONS}

The present study is the first combined economic and scientometric study that depicts a sketch of the global research activities on ectopic pregnancies. With regard to other disease entities, it can be stated that a mere total of about 8000 related publications highlights the need to foster research programmes on this problematic condition that endangers female health and human reproduction biology all around the globe. The lack of research productivity in low-income countries and their missing presence in international collaborations also exemplifies the need for public health approaches to help women in these parts of the world.

Acknowledgements We thank G Volante for expert editorial help. This study is part of a thesis project (JK).

Competing interests None declared.

Provenance and peer review Not commissioned; externally peer reviewed.

Open Access This is an Open Access article distributed in accordance with the Creative Commons Attribution Non Commercial (CC BY-NC 4.0) license, which permits others to distribute, remix, adapt, build upon this work non-commercially, and license their derivative works on different terms, provided the original work is properly cited and the use is non-commercial. See: http://creativecommons.org/ licenses/by-nc/4.0/

(C) Article author(s) (or their employer(s) unless otherwise stated in the text of the article) 2017. All rights reserved. No commercial use is permitted unless otherwise expressly granted.

\section{REFERENCES}

1. Marion LL, Meeks GR. Ectopic pregnancy: history, incidence, epidemiology, and risk factors. Clin Obstet Gynecol 2012;55:376-86.

2. Kirk E, Bottomley C, Bourne T. Diagnosing ectopic pregnancy and current concepts in the management of pregnancy of unknown location. Hum Reprod Update 2014;20:250-61.

3. Kao LY, Scheinfeld MH, Chernyak V, et al. Beyond ultrasound: $\mathrm{CT}$ and MRI of ectopic pregnancy. AJR Am J Roentgenol 2014;202:904-11.

4. Orazulike NC, Konje JC. Diagnosis and management of ectopic pregnancy. Womens Health 2013;9:373-85.

5. Alkatout I, Honemeyer U, Strauss A, et al. Clinical diagnosis and treatment of ectopic pregnancy. Obstet Gynecol Surv 2013;68:571-81.
6. van Mello NM, Mol F, Ankum WM, et al. Ectopic pregnancy: how the diagnostic and therapeutic management has changed. Fertil Steril 2012;98:1066-73.

7. Lermann J, Segl P, Jud SM, et al. Low-dose methotrexate treatment in ectopic pregnancy: a retrospective analysis of 164 ectopic pregnancies treated between 2000 and 2008. Arch Gynecol Obstet 2014;289:329-35.

8. Cecchino GN, Araujo Júnior E, Elito Júnior J. Methotrexate for ectopic pregnancy: when and how. Arch Gynecol Obstet 2014;290:417-23.

9. Hosni MM, Herath RP, Mumtaz R. Diagnostic and therapeutic dilemmas of cervical ectopic pregnancy. Obstet Gynecol Surv 2014;69:261-76.

10. Visconti K, Zite N. hCG in ectopic pregnancy. Clin Obstet Gynecol 2012;55:410-7.

11. Rausch ME, Barnhart KT. Serum biomarkers for detecting ectopic pregnancy. Clin Obstet Gynecol 2012;55:418-23.

12. Casikar I, Reid S, Condous G. Ectopic pregnancy: ultrasound diagnosis in modern management. Clin Obstet Gynecol 2012;55:402-9.

13. Hajenius PJ, Mol F, Mol BW, et al. Interventions for tubal ectopic pregnancy. Cochrane Database Syst Rev 2007:CD000324(Epub ahead of print: 27 Jan 2007).

14. Washington AE, Katz P. Cost of and payment source for pelvic inflammatory disease. Trends and projections, 1983 through 2000. JAMA 1991;266:2565-9.

15. Creanga AA, Shapiro-Mendoza CK, Bish CL, et al. Trends in ectopic pregnancy mortality in the United States: 1980-2007. Obstet Gynecol 2011;117:837-43.

16. Der EM, Moyer C, Gyasi RK, et al. Pregnancy related causes of deaths in Ghana: a 5-year retrospective study. Ghana Med J 2013;47:158-63.

17. Groneberg-Kloft B, Quarcoo D, Scutaru C. Quality and quantity indices in science: use of visualization tools. EMBO Rep 2009;10:800-3.

18. Groneberg-Kloft B, Fischer TC, Quarcoo D, et al. New quality and quantity indices in science (NewQIS): the study protocol of an international project. J Occup Med Toxicol 2009;4:16.

19. Gastner MT, Newman ME. From the cover: diffusion-based method for producing density-equalizing maps. Proc Natl Acad Sci U S A 2004;101:7499-504.

20. Groneberg DA, Rahimian S, Bundschuh M, et al. Telemedicine - a scientometric and density equalizing analysis. J Occup Med Toxicol 2015;10:38.

21. Quarcoo D, Brüggmann D, Klingelhöfer D, et al. Ebola and Its global research architecture-need for an improvement. PLoS Negl Trop Dis 2015;9:e0004083.

22. Schreiber M, Klingelhöfer D, Groneberg DA, et al. Patient safety: the landscape of the global research output and gender distribution. BMJ Open 2016;6:e008322.

23. Groneberg DA, Weber E, Gerber A, et al. Density equalizing mapping of the global tuberculosis research architecture. Tuberculosis 2015;95:515-22.

24. Gerber A, Klingelhoefer D, Groneberg DA, et al. Silicosis: geographic changes in research: an analysis employing density-equalizing mapping. J Occup Med Toxicol 2014;9:2.

25. Gerber A, Groneberg DA, Klingelhöfer D, et al. Gout: a critical analysis of scientific development. Rheumatol Int 2013;33:2743-50.

26. Brüggmann $\mathrm{D}$, Handl $\mathrm{V}$, Klingelhöfer $\mathrm{D}$, et al. Congenital toxoplasmosis: an in-depth density-equalizing mapping analysis to explore its global research architecture. Parasit Vectors 2015;8:646.

27. Pleger N, Kloft B, Quarcoo D, et al. Bacterial meningitis: a densityequalizing mapping analysis of the global research architecture. Int J Environ Res Public Health 2014;11:10202-14.

28. Brüggmann D, Mäule LS, Klingelhöfer D, et al. World-wide architecture of osteoporosis research: density-equalizing mapping studies and gender analysis. Climacteric 2016;19:463-70.

29. Brüggmann D, Wagner C, Klingelhöfer D, et al. Maternal depression research: socioeconomic analysis and density-equalizing mapping of the global research architecture. Arch Womens Ment Health 2017;20:25-37.

30. Brüggmann D, Elizabeth-Martinez A, Klingelhöfer D, et al. Endometriosis and its global research architecture: an in-depth density-equalizing mapping analysis. BMC Womens Health 2016;16:64

31. Brüggmann $D$, Löhlein LK, Louwen $F$, et al. Caesarean section - a density-equalizing mapping study to depict Its global research architecture. Int J Environ Res Public Health 2015;12:14690-708.

32. Bundschuh M, Groneberg DA, Klingelhoefer D, et al. Yellow fever disease: density equalizing mapping and gender analysis of international research output. Parasit Vectors 2013;6:331. 
33. Aleixandre-Benavent R, Simon C, Fauser BC. Trends in clinical reproductive medicine research: 10 years of growth. Fertil Steril 2015;104:131-7.

34. Brüggmann $\mathrm{D}$, Berges $\mathrm{L}$, Klingelhöfer $\mathrm{D}$, et al. Polycystic ovary syndrome: analysis of the global research architecture using density equalizing mapping. Reprod Biomed Online 2017;34:627-38

35. Brüggmann D, Pulch K, Klingelhöfer D, et al. Ovarian cancer: density equalizing mapping of the global research architecture. Int $J$ Health Geogr 2017; 16:3.

36. Kotepui M, Wannaiampikul S, Chupeerach C, et al. A bibliometric analysis of diets and breast cancer research. Asian Pac J Cancer Prev 2014:15:7625-8.

37. Moghimi M, Fathi M, Marashi A, et al. A scientometric analysis of 20 years of research on breast reconstruction surgery: a guide for research design and journal selection. Arch Plast Surg 2013:40:109-15.

38. Healy NA, Glynn RW, Scutaru C, et al. The h index and the identification of global benchmarks for breast cancer research output. Breast Cancer Res Treat 2011;127:845-51.

39. Glynn RW, Scutaru C, Kerin MJ, et al. Breast cancer research output, 1945-2008: a bibliometric and density-equalizing analysis. Breast Cancer Res 2010;12:R108.

40. Society AC. Cancer facts and figure 2015. Secondary cancer facts and figure 2015. http://www.cancer.org/research/cancerfactsstati stics/cancerfactsfigures2015/

41. Mund M, Kloft B, Bundschuh M, et al. Global research on smoking and pregnancy - a scientometric and gender analysis. Int J Environ Res Public Health 2014:11:5792-806.

42. Chen XL, Chen ZR, Cao ZL, et al. The 100 most cited articles in ectopic pregnancy: a bibliometric analysis. Springerplus 2016;5:1815.

43. Link AM. US and non-US submissions: an analysis of reviewer bias. JAMA 1998;280:246-7.

44. Groneberg-Kloft B, Scutaru C, Kreiter C, et al. Institutional operating figures in basic and applied sciences: scientometric analysis of quantitative output benchmarking. Health Res Policy Syst 2008;6:6:6

45. Goldner TE, Lawson HW, Xia Z, et al. Surveillance for ectopic pregnancy - United States, 1970-1989. MMWR CDC Surveill Summ 1993;42:73-85

46. Nagaya K, Fetters MD, Ishikawa M, et al. Causes of maternal mortality in Japan. JAMA 2000;283:2661-7.
47. Khan KS, Wojdyla D, Say L, et al. WHO analysis of causes of maternal death: a systematic review. Lancet 2006;367:1066-74.

48. Kalman S, Mitchell W, Marathe R, et al. Comparative genomes of Chlamydia pneumoniae and C. trachomatis. Nat Genet 1999;21:385-9.

49. Weström L, Joesoef R, Reynolds $G$, et al. Pelvic inflammatory disease and fertility. A cohort study of 1,844 women with laparoscopically verified disease and 657 control women with normal laparoscopic results. Sex Transm Dis 1992;19:185-92.

50. Cates W, Wasserheit JN. Genital chlamydial infections: epidemiology and reproductive sequelae. Am J Obstet Gynecol 1991:164:1771-81.

51. Black CM. Current methods of laboratory diagnosis of Chlamydia trachomatis infections. Clin Microbiol Rev 1997;10:160-84.

52. Miller WC, Ford CA, Morris M, et al. Prevalence of chlamydial and gonococcal infections among young adults in the United States. JAMA 2004;291:2229-36.

53. Cnattingius $\mathrm{S}$. The epidemiology of smoking during pregnancy: smoking prevalence, maternal characteristics, and pregnancy outcomes. Nicotine Tob Res 2004;6(Suppl 2):125-40.

54. Stovall TG, Ling FWSingle-dose methotrexate: an expanded clinical trial. Am J Obstet Gynecol 1993;168:1759-62.

55. Kadar N, Caldwell BV, Romero R. A method of screening for ectopic pregnancy and its indications. Obstet Gynecol 1981;58:162-6.

56. Nybo Andersen AM, Wohlfahrt J, Christens P, et al. Maternal age and fetal loss: population based register linkage study. BMJ 2000;320:1708-12.

57. Tanaka T, Hayashi H, Kutsuzawa T, et al. Treatment of interstitial ectopic pregnancy with methotrexate: report of a successful case. Fertil Steril 1982;37:851-2

58. Kadar N, DeVore G, Romero R. Discriminatory hCG zone: its use in the sonographic evaluation for ectopic pregnancy. Obstet Gynecol 1981:58:156-61.

59. Pouly JL, Mahnes H, Mage G, et al. Conservative laparoscopic treatment of 321 ectopic pregnancies. Fertil Steril 1986:46:1093-7.

60. Weström L, Bengtsson LP, Mårdh PA. Incidence, trends, and risks of ectopic pregnancy in a population of women. $\mathrm{Br} M e d \mathrm{~J}$ 1981;282:15-18.

61. Peyron R, Aubény E, Targosz V, et al. Early termination of pregnancy with mifepristone (RU 486) and the orally active prostaglandin misoprostol. N Engl J Med 1993;328:1509-13. 